\title{
Risk management at the stage of design of high-rise construction facilities
}

\author{
Violetta Politi ${ }^{1, *}$ \\ ${ }^{1}$ Moscow State University of Civil Engineering; 26, Yaroslavskoe sh., Moscow, 129337, Russia
}

\begin{abstract}
This paper describes the assessment of the probabilistic risk of an accident formed in the process of designing a technically complex facility. It considers values of conditional probabilities of the compliance of load-bearing structures with safety requirements, provides an approximate list of significant errors of the designer and analyzes the relationship between the degree of compliance and the level of danger of errors. It describes and proposes for implementation the regulated procedures related to the assessment of the safety level of constructive solutions and the reliability of the construction process participants.
\end{abstract}

\section{Introduction}

High-rise multi-profile buildings should be classified as technically complex construction projects. As we know, with the increase in the number of characteristics and elements of any facility, the number of probabilities of failures in the operation of the system elements also increases. Traditionally, the reliability of load-bearing structures is the main indicator ensuring safety of operation at any stage of the life cycle for the construction facility. However, for a complex construction facility, safety must also be ensured by the reliability of engineering systems and equipment. Also, special attention is paid to the foundation, which bears a colossal load. The most important factors for ensuring the safety of people inside a high-rise building include fire protection. Therefore, it is necessary to solve the problems of ensuring reliability of both the structural part and the operation of the building, strive to reduce the material consumption, optimize the ventilation and hydraulic regime, and also the energy consumption regime at the design stage of a complex facility. It is possible to manage the risk of erecting and operating a technically complex facility on the basis of the development and implementation of regulated procedures related to the assessment of the safety level of constructive solutions and the reliability of both engineering systems and all construction process participants.

\section{Materials and methods}

Distinctive features of high-rise construction are high load on load-bearing structures, in particular, on bases and foundations, the increased importance of the impact of natural and man-made factors, such as seismic impacts, solar radiation, aerodynamics, vibrations, and uneven load of structural elements [1]. These features require increased attention of

\footnotetext{
*Corresponding author: polity violca@list.ru
} 
designers to the selection of design and space-planning solutions. It should be noted that for high-rise buildings, complicated in the architectural and planning terms and with a large extension of engineering networks, the most important factors of trouble-free operation are the correct designer's choice of automatic heating, ventilation, gas supply, electricity, and water supply systems.

All of the above factors indicate the complexity of designing and operating high-rise buildings and, as a consequence, the high probability of errors in the design, construction and operation of a complex construction facility.

The risk of an accident is a vector quantity consisting of an adjustable part, for example, a facility risk, and an unadjustable part generated by the external environment.

A facility risk is the risk that can be subject to the targeted effect, and which is formed by errors of designers, builders, supervisors and controlling organizations.

In most cases, accidents of buildings and structures, as well as the failure of engineering systems supporting the life of the consumer, occur as a result of a collision of two independent events - the appearance of an external unintended impact and effects determined by a set of human errors that led to a reduction in the structural safety of the facility $[3,4]$.

The forecast of an accident risk of construction facilities on the basis of the classical probabilistic approach is impossible for two reasons. First, accidents of buildings and structures are very rare events, and second, unpredictable human errors allowed in the process of designing, erecting and operating a construction facility, introduce significant uncertainty in the response (behavior) of the supporting frame of the facility to external influence. Since the risk of an accident and the degree of uncertainty of the technical state of the facility's structural framework are closely related concepts, the accident risk assessment should be based on a logic-probability approach based on probability theory theorems, the methods of the theory of fuzzy sets, fuzzy logic techniques and decisionmaking methods under uncertainty [5].

The values of the actual risk of an accident, physical (structural) wear and safe operating life of buildings and structures are also interrelated. To determine these values, the accident risk distribution law should be used, which is an integral indicator of the level of structural safety of a construction facility.

The probability of occurrence of the risk of an accident at a complex construction facility should be carried out on the basis of functioning of an expert system, which is the result of the interaction of the expertise of specialists, the mathematical apparatus and information technology.

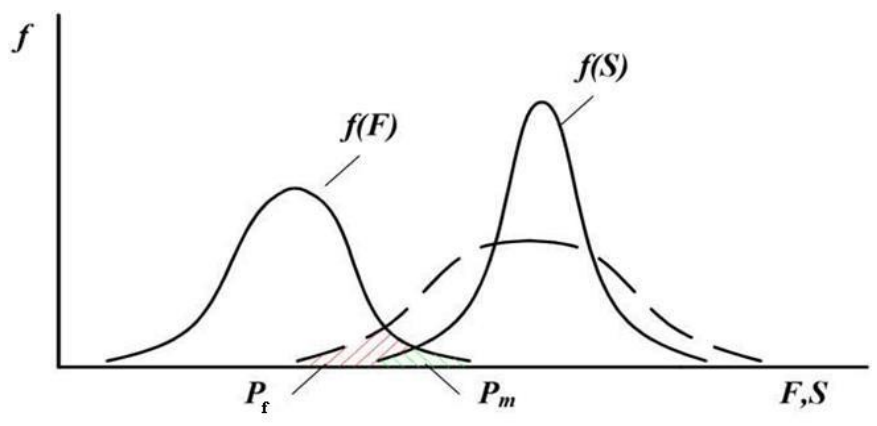

Fig. 1. The law of distribution of actions to the object.

( $\mathrm{F}$ - the force of the impact; $\mathrm{S}$ - the resistance force; $\mathrm{P}_{\mathrm{F}}-$ the fact of the likelihood; $\mathrm{P}_{\mathrm{T}}$-the theoretical probability of an accident; «point line» - the influence of human errors on the operation of the law) 


\subsection{About the Accident Risk Distribution Law}

So, it is known from the practical experience that the determining factors for the occurrence of emergency situations are the errors of the construction participants. It is also known that by the end of the facility construction, the actual probability of an accident $\left(P_{f}\right)$ in comparison with the theoretical $\left(P_{t}\right)$ increases several times. Further, the actual probability of an accident on an unlimited number of new buildings can be represented as:

$$
P_{f}=P_{t}+P_{d}
$$

$P_{d}$ - additional probability generated due to errors of the construction process participants (designers, builders, experts, supervisory and controlling organizations).

To determine $P_{d}$, the hypothesis theorem (Bayes formula) is used, which allows one to recalculate the a priori probabilities in terms of information about the errors committed. Two opposite events are introduced: $B$ - errors in erecting load-bearing frameworks of buildings exist, $B^{*}-$ no errors. Events $B$ and $B^{*}$ form a complete group of incompatible events, are identified in the construction process, and before the construction starts, the set $C$ is empty.

The following designations are accepted:

$\mathrm{P}\left(\mathrm{B}^{*}\right)=v-$ the probability that there are no errors in the constructed building,

$\mathrm{P}(\mathrm{B})=(1-v)-$ the probability of the opposite event.

A priori (before construction) probabilities of occurrence and non-occurrence of an accident of buildings (structures) are known and are respectively equal to $P_{m}$ and $\left(1-P_{m}\right)$. The ratio follows from the Bayes formula:

$$
P_{d}=\frac{P_{m} P\left(\frac{C}{A}\right)}{P_{m} P\left(\frac{C}{A}\right)+\left(1-P_{m}\right) P\left(\frac{C}{A^{*}}\right)}
$$

where $\mathrm{P}(\mathrm{C} / \mathrm{A})$ is the probability of the event $\mathrm{C}$, provided that the accident occurs; $\mathrm{P}\left(\mathrm{C} / \mathrm{A}^{*}\right)$ is the probability that the event $\mathrm{C}$ will occur.

Based on the use of fuzzy logic techniques, we can adopt the following relations: $\mathrm{P}\left(\mathrm{C} / \mathrm{A}^{*}\right)=\mathrm{v}$, in turn, $\mathrm{P}(\mathrm{C} / \mathrm{A})=1-\mathrm{v}$.

Indeed, if an accident does not occur during the construction or operation of the facility, then the event $B^{*}$ occurs, in the opposite case, the event $B$ occurs.

After substituting these equalities in the Bayesian relation, we have:

$$
P_{d}=\frac{P_{m}(1-v)}{v}
$$

The addition of two probabilities gives the following relationship: $\frac{\mathrm{P}_{\mathrm{d}}}{\mathrm{P}_{\mathrm{m}}}=\frac{1}{\mathrm{v}}$, where $v$ is the structural reliability of the building.

It is important to understand that the probability $P_{t}$ exists and can hypothetically arise if the project requirements will not be violated in the design and erection of the bearing framework of the building. However, in practice, such violations always occur, and then the ratio of the two quantities will always be greater than one, namely $\left.\left(P_{f} / P_{t}\right)>1\right)$. This ratio shows how many times the actual risk of an accident is higher than the theoretical risk taken into account in the building design. Consequently, it can be adopted as an integral indicator of the technical state of the load-bearing framework of a high-rise construction facility. Therefore, the result of calculating this ratio can be correlated with the magnitude of the risk assessing the probability of an accident at the construction facility $r$ :

$$
r=P_{f} / P_{t}=1 / v
$$

However, there are no statistical data on the possible values of $r$. Therefore, in order to find the distribution law for the probability density of the occurrence of a random variable $r$ on an unbounded set of new non-typical high-rise buildings, the author sets forth the following axioms based on the laws of logic and practice in the construction industry:

Axiom 1. The probabilities of $\mathrm{r} \leq 1$ are equal to zero. 
Axiom 2. The distribution curve is strictly asymmetric; the mode of the random variable $r$ is shifted to the left of the mean value.

The one-parameter Rayleigh distribution, which has the following form, corresponds to the above axioms:

$$
f(x)=(r-1) / \sigma \sigma^{2} \exp \left[-(r-1) 2 / 2 \sigma^{2}\right]
$$

It is known that in the distributions the parameter $\sigma$ is related to the mathematical expectation (average value) of the accident risk $R$ as follows:

$$
\mathrm{R}=1+1,25 \sigma
$$

To determine the mean value of the risk $R$, one should use the following relation derived from (3):

$$
\mathrm{R}=1 / \mathrm{M} v
$$

where $M v$ - is the mean value (mathematical expectation) of a random variable $v$ which numerical values are in the range from 0 to 1 .

\section{Results}

On the Management of Building Accident Risk at the Design Stage

Below is a list of comments most often encountered when reviewing project documentation in the section "Constructive solutions and space-planning solutions" in terms of design solutions:

- Design tasks and design documentation do not specify or incorrectly specify the identification characteristics of the buildings (structures) being designed (reconstructed) (including the belonging to hazardous production facilities specifying the hazard class, the level of responsibility of buildings and structures, the general seismic zoning map adopted to determine design seismicity in the design, etc.);

- Calculation substantiation of design solutions for two groups of limiting states and calculations of the influence of new construction on the structures of the surrounding development are not provided;

- Calculations for an emergency situation (calculations of resistance to a progressive collapse) are not provided for buildings and structures with an increased level of responsibility and for public and industrial buildings with a normal level of responsibility;

- Information is not provided on the strength and deformation characteristics of the soil at the base of the foundations, as well as drawings with characteristic geological sections with the foundations marked;

- The results of determining aerodynamic coefficients based on the results of purging of models of structures in wind tunnels or on recommendations developed by specialized organizations are not provided for buildings and structures with an increased level of responsibility;

- There is no provision for scientific and technical support in the design, manufacture and installation of structures, as well as their technical monitoring during erection and operation for buildings and structures with an increased level of responsibility;

- There are no construction tasks for the arrangement of process equipment with loads and references;

- The results of a survey of the technical condition of the erected buildings and structures necessary for the development of project documentation are not performed and are not provided.

Obviously, to increase the safe resource of the constructed facility, it is necessary to develop procedures for regulating the possible risk of an accident planned for the facility erection. The initial stage of regulation is to predict the probability of occurrence of an accident risk at the initial, design stage. The information base for predicting can be an analysis of the effectiveness of quality management systems, which applies to each 
construction process participant. According to practical observations, a high level of quality management systems ensures a high level of safety of the designed facility. It is possible to predict the probability of occurrence of an accident risk using equation (6), and the average reliability levels $M p$ of the groups of the same type of bearing framework structures are determined according to the results of the examination of the efficiency of the quality systems used by potential construction process participants $[6,7,8]$.

Table 1. Requirements of ISO 9001 for elements of quality management systems.

\begin{tabular}{|c|c|}
\hline Pos. No. & Elements of quality management systems \\
\hline 1. & Availability of quality policy and quality work motivation system \\
\hline 2. & Correspondence of engineering and workers' professions to the production profile \\
\hline 3. & $\begin{array}{l}\text { Availability of actualized programs for upgrading the skills of different categories of } \\
\text { employees }\end{array}$ \\
\hline 4. & $\begin{array}{l}\text { Compliance of mechanisms and equipment with the requirements of the quality of } \\
\text { technological operations }\end{array}$ \\
\hline 5. & $\begin{array}{l}\text { Availability of a maintenance system and a system for documenting the procedures of } \\
\text { performing technological operations }\end{array}$ \\
\hline 6. & $\begin{array}{l}\text { Regular internal audit conducted to assess the effectiveness of the quality management } \\
\text { system }\end{array}$ \\
\hline 7. & $\begin{array}{l}\text { Availability of programs, techniques, experts with definition of their responsibility, } \\
\text { forms of documentation and registration of incoming and production quality control of } \\
\text { products }\end{array}$ \\
\hline 8. & $\begin{array}{l}\text { Availability of equipment, metrological and laboratory support of procedures for } \\
\text { identifying product quality }\end{array}$ \\
\hline
\end{tabular}

The average reliability level $M p$ of the structure group can be estimated from the probability $P(B)$ of its compliance with the requirements of regulatory documents in terms of ensuring strength, rigidity and stability. Indeed, it follows from the equation of the total probability that

$$
\mathrm{Mp}=\mathrm{P}(\mathrm{B})=\sum \mathrm{P}(\mathrm{B} / \mathrm{qi}) \mathrm{P}(\mathrm{qi})
$$

where $\mathrm{q}=\{\mathrm{qi}\}=\left\{\mathrm{MCD}, \mathrm{M}^{*} \mathrm{BD}, \mathrm{MB}^{*} \mathrm{D}, \mathrm{MBD}^{*}, \mathrm{M}^{*} \mathrm{~B}^{*} \mathrm{D}, \mathrm{M}^{*} \mathrm{BD}^{*}, \mathrm{MB}^{*} \mathrm{D}^{*}\right.$, $\left.M^{*} B^{*} D^{*}\right\}$ is the complete group of events including the following independent events: $M-$ there are no errors of suppliers of materials (products); B - there are no errors of builders; $\mathrm{D}$ - there are no errors of designers; $\mathrm{M}^{*}, \mathrm{~B}^{*}$ and $\mathrm{D}^{*}$ are events opposite to events $\mathrm{M}, \mathrm{B}$ and D.

The conditional probabilities $P(B / q i)$ in this equation are invariants that have the meaning of the probability of the correspondence of load-bearing structures to safety requirements while observing certain conditions (Table 2).

Table 2. Values of the conditional probabilities of compliance of load-bearing structures with safety requirements.

\begin{tabular}{|c|c|ll|}
\hline Pos. No. & Probability value & \multicolumn{1}{c|}{ Comment } \\
\hline 1. & $\mathrm{P}(\mathrm{B} / \mathrm{q} 1)=1$ & - & no errors of all construction participants \\
\hline 2. & $\mathrm{P}(\mathrm{B} / \mathrm{q} 2)=\mathrm{a}$ & - & there are only suppliers' errors \\
\hline 3. & $\mathrm{P}(\mathrm{B} / \mathrm{q} 3)=\mathrm{b}$ & - & there are only builders' errors \\
\hline 4. & $\mathrm{P}(\mathrm{B} / \mathrm{q} 4)=\mathrm{c}$ & - & there are only designers' errors \\
\hline 5. & $\mathrm{P}(\mathrm{B} / \mathrm{q} 5) \cong \mathrm{ab}$ & - & no errors of designers only \\
\hline 6. & $\mathrm{P}(\mathrm{B} / \mathrm{q} 6) \cong \mathrm{ac}$ & - & no errors of builders only \\
\hline 7. & $\mathrm{P}(\mathrm{B} / \mathrm{q} 7) \cong \mathrm{bc}$ & - & no errors of suppliers only \\
\hline 8. & $\mathrm{P}(\mathrm{B} / \mathrm{q} 8) \cong \mathrm{abc}$ & - & there are errors of all construction participants \\
\hline
\end{tabular}

Invariants in aggregate represent a priori information that can be compiled from an analysis of the causes of accidents. 
In the Russian Federation, $\sim 80 \%$ of accidents occur due to errors made by the construction process participants, including $\sim 20 \%$ due to the fault of suppliers, $\sim 50 \%$ due to the fault of builders, and $\sim 10 \%$ due to the fault of designers. Thus, $\mathrm{a}=0,8, \mathrm{~b}=0,5, \mathrm{c}=0,9$.

If we designate the probabilities of the independent events $M, B$ and $D$ as $P(M)=\mu . m$, $P(B)=\mu . b, P(D)=\mu . d$, then the following mathematical model follows from the total probability equation:

$\mathrm{Mp}=\mu . \mathrm{m} \mu . \mathrm{b} \mu . \mathrm{d}+0,8(1-\mu . \mathrm{m}) \quad \mu . \mathrm{b} \mu . \mathrm{d} \quad+0,5 \mu \cdot \mathrm{m}(1-\mu . \mathrm{b}) \quad \mu . \mathrm{d}+\quad 0,9 \mu \cdot \mathrm{m} \mu . \mathrm{b}(1-$ $\mu . d)+0,4(1-\mu \mathrm{m})(1-\mu . b) \quad \mu . d++0,72(1-\mu . m) \quad \mu . b(1-\mu . d)+0,45 \mu . m \quad(1-\mu . b)(1-$ $\mu . d)+0,36(1-\mu . m)(1-\mu . b)(1-\mu . d)$

In the equation, the values $\mu . d, \mu . m$ and $\mu$. bhave the meaning of the degrees of compliance of load-bearing structures with the requirements of regulatory documents. The equation allows to predict the average level of reliability $M p$ of groups of structures of the bearing framework, both at the stage of the building design, and at the stage when the facility project already exists

\section{Discussion}

Let's consider the case of declaring the level of structural safety planned for the erection of a building (structure) when the facility project already exists. When determining $\mu . d$, the expert's tasks are:

1) to track the presence of significant (weighty) errors in the project (Table 3);

2) to assess the level of danger of errors found in the project;

3 ) to take measures to eliminate the errors found.

Table 3. Sample list of significant designer's errors.

\begin{tabular}{|l|l|}
\hline $\begin{array}{l}\text { Error } \\
\text { No. }\end{array}$ & Characteristic of possible errors in the design of structural elements \\
\hline 1. & $\begin{array}{l}\text { The physical and mechanical characteristics of soils adopted in the project do not } \\
\text { correspond to the actual state of the foundation. There are no laboratory tests of soil } \\
\text { samples with undisturbed structure }\end{array}$ \\
\hline 2. & $\begin{array}{l}\text { When choosing the foundation calculation model, the geological engineering surveys } \\
\text { did not reveal or take into account the characteristic dependences of the soil } \\
\text { deformation under load }\end{array}$ \\
\hline 3. & $\begin{array}{l}\text { Dimensions of the foundation and the position of the masses on the facility plan do } \\
\text { not ensure the uniformity of settling }\end{array}$ \\
\hline 4. & $\begin{array}{l}\text { The design scheme of the supporting frame does not correspond to its actual work } \\
\text { under load }\end{array}$ \\
\hline 5. & $\begin{array}{l}\text { When entering the initial data in the software, errors in dimensions and values of } \\
\text { loads, resistances, and rigidity were made. The calculation is not duplicated according } \\
\text { to another software }\end{array}$ \\
\hline 6. & $\begin{array}{l}\text { Non-compliance of the designed nodal connections of the framework elements with } \\
\text { node rigidity estimation scheme adopted in the design }\end{array}$ \\
\hline 7. & $\begin{array}{l}\text { Bonded structures do not provide the required rigidity of the supporting frame of the } \\
\text { facility }\end{array}$ \\
\hline
\end{tabular}

The level of danger of gross errors found in the project is estimated according to a special rule (Table 4).

Table 4. Relationship of the degree of compliance with the level of danger of errors made.

\begin{tabular}{|l|l|l|}
\hline Error danger level & \multicolumn{1}{|c|}{$\begin{array}{c}\text { Degree of effect of errors found on } \\
\text { safety in a linguistic form }\end{array}$} & Project reliability level \\
\hline First & Virtually no effect & 0.939 \\
\hline Second & Imperceptible effect & 0.987 \\
\hline
\end{tabular}




\begin{tabular}{|l|l|l|}
\hline Third & Insignificant effect & 0.686 \\
\hline Fourth & Significant effect & 0.568 \\
\hline Fifth & Very significant effect & 0.828 \\
\hline Sixth & Extremely high effect & 0.500 \\
\hline
\end{tabular}

The danger levels and the degree of compliance are determined for each significant error found in the project. Together they form a fuzzy set of project quality assessments. In accordance with the algebra of fuzzy sets, the final numerical estimate of the project is determined as $\mu \mathrm{d}=\min \{(\mu . \mathrm{d}) \mathrm{i}\}$.

To determine $\mu . \mathrm{m}$ and $\mu . \mathrm{b}$, a hypothesis is introduced about the direct dependence of the safety level of constructive solutions of afacility on the effectiveness of the functioning of quality systems of organizations participating in the investment construction process.

The task of the expert is to assign the degrees of correspondence $(\mu . \mathrm{m}) \mathrm{i}$ and $(\mu . \mathrm{b}) \mathrm{i}$ for all elements of the quality system (Table 1).

By analogy with $\mu \mathrm{d}$, the final numerical estimates of the quality systems of the supplier organization and the contractor organization are determined as: $\mu \mathrm{m}=\min \{(\mu \mathrm{m}) \mathrm{i}$ \},$\mu b=\min \{(\mu . b) \mathrm{i}\}$.

The technology of declaring the safety of constructive solutions of a facility at the stage of design development consists of the following operations:

1. A "tree" of the states of the facility is formed, which is a hierarchical sequence of the erection of groups of the same type of structures of the supporting framework.

2. A numerical estimate of the project $\mu . d$. is determined.

3 . Based on the results of diagnostics of quality systems, $\mu . m$ and $\mu . b$ are assigned for all construction process participants.

4. According to the equation (8), the values of the average reliability levels Mp of all groups of structures of the supporting framework of the facility are determined.

5. According to the equation (8), the actual risk of an accident $\mathrm{R}$ after the facility erection is determined, and this risk is compared with the normal risk of an accident Rn.

6. If $\mathrm{R}>\mathrm{Rn}$, a diagram is built for the average predicted reliability levels $\mathrm{Mp}$ in groups of the same type of structures of the supporting framework of the facility, specifying the standard normal Rn level of the structural reliability.

7. The diagram identifies the construction participants which potentially will bring the greatest risk of the accident to the facility, and an administrative decision is made based on the information in p. 3 .

\section{Conclusions}

The methodology for calculating the risk of an accident and the safe residual life of buildings and structures are closely related to procedures for assessing and regulating the level of structural safety of both buildings under construction and in operation.

The application of this methodology makes it possible to determine the "contribution" of each group of structures of the supporting framework to the value of the accident risk of the facility under study; calculate the safe residual life of the facility and make a prediction of the period of operation, after which measures should be taken at the facility to reduce the risk of an accident.

\section{References}

1. I. Ilin, O. Iliashenko, A. Levina, Vision 2020, 768-781 (2016)

2. I. Ilin, A. Anisiforov, WSEAS Transactions on Business and Economics, 11, 757-764 (2014) 
3. O. Kalinina, O. Valebnikova, Advances in Intelligent Systems and Computing, 692, 1315-1322 (2018) DOI - 10.1007/978-3-319-70987-1_139

4. A. Zaychenko, S. Gutman, O. Kalinina, Advances in Intelligent Systems and Computing, 692, 453-462 (2018) DOi - 10.1007/978-3-319-70987-1_48

5. V. Kankhva, Procedia Engineering, 165, 1300-1304 (2016) DOI:10.1016/j.proeng.2016.11.855

6. V. Kankhva, MATEC Web of Conferences, 106, 08027 DOI: 10.1051/matecconf/201710608027

7. E. Nezhnikova, IOP Conf. Series: Earth and Environmental Science, 90, 012161 (2017) DOI:10.1088/1755-1315/90/1/012161

8. A. Jones, G. Fallon, R. Golov, European Business Review, 12, 187-197 https://doi.org/10.1108/09555340010336871 